\title{
La biblioteca escolar y la formación lectora'
}

\section{School Library and Reader Formation Process}

Patricia Calonje Daly*

Los hombres solo adquieren su condición humana con ese rumor de las historias que les acompañan a lo largo de su vida.

Michel Tournier

\section{Resumen}

Este artículo discute los conceptos ideológicamente legitimados que dan sustento a las nociones socialmente predominantes acerca de la relación entre formación lectora y biblioteca escolar $y$, alternativamente, plantea las condiciones que deberían ser asumidas por esa misma relación para que se torne enriquecedora: grosso modo, el sentido de las prácticas que comprometen a la totalidad de la comunidad educativa, la creación de entornos favorables, las interacciones con diversos tipos de texto, las nuevas relaciones con los textos, las formas de organización diferentes, el carácter de los procesos para hacerse lector, el sentido del conocimiento, la biblioteca y los maestros y los bibliotecarios como mediadores.

\section{Palabras clave:}

Biblioteca escolar, formación lectora, condiciones para el desarrollo de la biblioteca escolar, bibliotecarios, procesos lectores, lectura, biblioteca y escuela.

\section{Abstract}

This article points out the relation between the school library and the reader formation as legitimated concepts that support predominant notions. Indeed, it supports the conditions that should be assumed by that same relationship for enriching the learning process. In this case, the educative community should be the main participant in this relation. It can create favorable environments, interactions with multiple kinds of texts, new relationships with texts, different kinds of organization, making the process of becoming a reader, knowledge purpose, finally library and teachers, and librarians as mediators.

Key words:

School library, reader formation, conditions for developing a school library, librarians, reading processes, reading, library and school.

Artículo recibido el 1 de febrero de 2008 y aprobado el 12 de mayo de 2008

1 Este artículo se deriva de resultados parciales de la investigación “Caracterización de las bibliotecas de las instituciones escolares oficiales de una comuna de la ciudad de Cali: Condiciones que ofrecen para la formación de lectores", financiada por la Universidad del Valle, de la cual son autoras las profesoras Patricia Calonje Daly y Gloria Amparo Rodríguez Barreneche. Con algunas modificaciones fue presentada como ponencia en el "Seminario de Bibliotecas Escolares. Identidad y relaciones con su entorno" realizado en Cali el 14 y el 15 de junio de 2007.

* Profesora Titular del Instituto de Pedagogía y Educación de la Universidad del Valle. patcalonje@telesat.com.co 
¿Quién impugna la importancia de las bibliotecas escolares en la formación lectora? Nadie, por supuesto. Sin embargo, la cruda verdad de la realidad empírica no hace sino refrendar la idea contraria. Semejante contradicción es aberrante. Con el propósito de analizar este problema presento estas líneas.

Para iniciar, quiero reflexionar sobre una de las muchas formas en que en el imaginario educativo se concibe la relación biblioteca escolar y formación lectora, que merece discutirse por el peso y el arraigo que tiene hoy día en el mundo de la escuela. Según esta idea, la biblioteca escolar contribuye a formar lectores solo por el hecho de existir, así sea en condiciones precarias: locales inadecuados, colecciones obsoletas y/o deterioradas, mínimo presupuesto, cuando no inexistente, acceso restringido, ausencia de préstamo externo, personal no idóneo, en especial en lo que se relaciona con el cargo de bibliotecario. Ahora bien, este reconocimiento es en realidad un desconocimiento del papel que juega la biblioteca en los procesos formativos, principalmente en aquellos que permiten el conocimiento y dominio del lenguaje escrito. Al atribuirle bondades casi sacras a este espacio fundamentándose en lugares comunes - "la biblioteca es el templo de la sabiduría", "la biblioteca encierra tesoros, etc."-, se dan por sentados sus vínculos con la lectura y con el mundo de lo escrito, dejando de lado la consideración de su propia especificidad como construcción social y cultural, es decir, las funciones que se le reconocen socialmente, su forma particular de inscripción en la vida de la escuela, su articulación con el proyecto educativo institucional y con el programa escolar, sus metas y las condiciones requeridas para cumplirlas.

Esta visión, además de sacralizadora, es simplista, porque asume su articulación con la formación lectora como natural. Vuelve natural lo que tiene un carácter eminentemente social. Relaciones y conceptos que son resultado de elaboraciones humanas, que son intrínsecamente culturales (es decir, elaborados a partir de un proceso de significación), son considerados como naturales, como si pudieran existir sin la intervención de los seres humanos, como si siempre hubieran estado allí, como el aire, como el agua, como el vuelo de las aves. ¿Quién discute la existencia del aire, del agua, del vuelo de los pájaros? $\mathrm{Al}$ volverse indiscutibles se convierten en verdades de piedra: ya no hacen parte de procesos de pensamiento ni requieren ser problematizadas.

El ejercicio de desnaturalizar una idea como esta tiene un sentido preciso: reflexionar sobre los elementos vinculantes que hacen posible esta relación, sus condiciones de posibilidad, de materialización, y su papel y ubicación en el contexto institucional y social en el que está anclada; permite develar el significado asignado a la biblioteca escolar, el en que como explica y concreta estos vínculos, la definición de un norte, de unos retos y de una propuesta que permita alcanzar sus propósitos.

\section{La biblioteca escolar y el jardín secreto}

Para situar unos primeros elementos sobre las condiciones requeridas para que la biblioteca escolar pueda ser realmente un espacio que contribuye a la formación lectora, me apoyaré en el símil establecido por Gustavo Martín Garzo (2003) para reflexionar sobre las orientaciones que propone para enseñarle a un niño a leer. La comparación la establece entre los libros y el jardín secreto, uno de los espacios fundamentales donde transcurre la novela homónima, un clásico de la literatura infantil y juvenil, cuya autora es la escritora inglesa Frances Hodgson Burnett (1994).

Para hacer posible el desarrollo propuesto cambiaré uno de los referentes del símil (el de los libros por el de la biblioteca escolar) y ampliaré la reflexión con el aporte de nuevos elementos, a fin de mostrar por qué no basta solo con que una escuela disponga de una biblioteca de cualquier manera, o que los estudiantes y profesores se limiten a saber de su existencia. Mary Lennox, la protagonista de El jardín secreto, al deambular por el terreno que ocupa la casa de un tío suyo donde ha llegado a vivir después de la muerte de sus padres, da con un lugar que, por sus características, atrae su interés: un jardín cercado por un alto muro por el que escalan enredaderas y por el que se asoman las copas de varios árboles. Lo que alcanza a ver y a imaginarse Mary de este lugar la impacta y la maravilla de tal modo que busca por 
todos los medios la forma de entrar en él. Ahora bien, al igual que sucede con la niña, que se siente atraída por conocer y explorar el espacio escondido del que logra entrever apenas algunos detalles que llaman profundamente su atención, la biblioteca escolar también puede constituirse en centro de interés para estudiantes y profesores. ¿Qué requiere para despertar en ellos el deseo de explorarla y de frecuentarla asiduamente? Todo depende del estado en que se encuentre, del tipo de dotación de que disponga, del esquema organizativo de que esté dotada y de cómo funcione, del ambiente y de la atención que brinde, de los servicios y programas que privilegie y del sentido que les otorgue.

Lo que quiero mostrar al establecer esta comparación es que no es suficiente con que una biblioteca escolar exista, que esté allí, de cualquier manera. Por el contrario, es necesario que resulte atrayente para el que se la topa, que al igual que el jardín secreto, lleno de vida y de símbolos que hablan del mundo y de la vida, que proyecta una visión que invita a Mary, a Colin, su primo, un niño triste y enfermizo, y a Dickon, el hermano de una de las criadas de la casa, a explorar y a conocer todos sus vericuetos, se constituya en un espacio que lleve a estudiantes y maestros a buscar la puerta por la que se accede a él. Si la niña encuentra el jardín en el que descubre un universo maravilloso, hasta cierto punto anticipado pero a la vez sorprendente, se debe a que, por una parte, se siente atraída a conocer lo que hay en él, al anticipar lo que guarda y, de otra, porque cuenta con la ayuda de un petirrojo, que es quien le proporciona la llave para entrar en él.

¿Qué tiene que hacer entonces la biblioteca para que maestros y estudiantes hagan parte activa no solo del lugar físico, sino del mundo que ofrecen los libros, de experiencias que les permitan asumirse como lectores, aprender a utilizar la información para construir conocimientos? Siguiendo mi propio símil, la posibilidad de encontrar la puerta que permite el ingreso al universo de la biblioteca escolar así como la de habitarlo y de convertirlo en un espacio vital, estará dada por lo que pueda ofrecer a niños y jóvenes, por la mediación que entre ellos y este mundo lleven a cabo el bibliotecario, profesores y otras personas a cargo de ella. Puede suceder que la mediación no incida en todos de la misma manera, que para algunos demore en producir los efectos esperados, pero esta es una situación que no ha de inquietar siempre y cuando exista para todos, sin distinciones, la posibilidad de ingresar en la biblioteca, y siempre que lo que lo albergue logre despertar, por su variedad y diversidad, el interés por visitarla y el deseo de conocerla en toda su extensión. La posibilidad de frecuentar el jardín asiduamente, de habitarlo, de participar de todo lo que ofrece y de darle más vida de la que posee, se produce por la intervención de Mary, que propone su arreglo, de Dickon, que, con sus conocimientos sobre plantas, desyerba el lugar, siembra flores, y por la mediación de un jardinero que, en su calidad de protector del lugar, los acoge y apoya sus iniciativas. $\mathrm{Al}$ igual que ha ocurrido en el jardín, el desarrollo y la renovación de la biblioteca escolar y el encuentro significativo con su espacio pueden darse y perdurar siempre y cuando existan mediadores que piensen en función de los intereses y expectativas de los lectores, y que sirvan de puentes entre ellos y el material escrito, cualquiera que sea su soporte, para incentivar relaciones significativas y gratificantes con este mundo.

A semejanza del jardín secreto, campo propicio para el florecimiento de una sólida amistad entre Mary Lennox, Colin y Dickon, es decir, para crear otros mundos posibles, la biblioteca escolar puede ofrecer un espacio vital a estudiantes para apoyar su proceso de aprendizaje de la lectura, no solo para que sientan el deseo de aprender a leer, sino también para hacerse y ser lectores. Pero, insisto, solo podrá hacerlo si se dota de determinadas condiciones que han de ser ofrecidas a todos los estudiantes, aun a aquellos que no saben leer convencionalmente todavía. Encontrar el mediador que proporcionará la llave de acceso a la biblioteca y la posibilidad de hacer parte activa de ella representa, por ejemplo, para los niños que están empezando su escolaridad, la oportunidad de conocer o de ampliar su saber sobre la diversidad textual existente en la sociedad, de rodearse de lectores, de modelos de expertos lectores, de empezar a hacer parte de una comunidad lectora y escritora y de participar en experiencias 
en las que los mediadores, al asumir el papel de intérpretes, creen las condiciones para que puedan leer en y a través de ellos².

Es bueno subrayar que si bien es cierto que Mary Lennox logra ingresar al jardín por la ayuda ofrecida por el petirrojo, también lo es que el encuentro con este espacio se produce gracias a la búsqueda que emprende para encontrar la puerta de acceso. La exploración que la niña y sus dos compañeros realizan en el lugar, los descubrimientos que hacen en relación con él y con respecto a sus propias vidas, los cambios que se suscitan en ellos, son resultado de las posibilidades que el jardín les ofrece, de las experiencias que debido a su influencia y por su propia decisión realizan. También son resultado de la forma en que deciden afrontar sus problemas, de la ayuda mutua que se dan y de los esfuerzos que emprenden en común para solucionarlos. La presencia y persistencia del deseo de conocer en Mary, Colin y Dickon, su capacidad de empuje y de resistencia constituyen la fuerza que incide en la transformación del jardín, de sus vidas y de las de los que los rodean. Así como sucede con el jardín, la biblioteca puede incentivar en sus usuarios el deseo de conocerla, explorarla y de hacerlos parte activa de sus realizaciones; pero para lograrlo ha de contar con una serie de condiciones que en su desarrollo den sentido a su existencia en la escuela. Asimismo, la posibilidad de contribuir a que los estudiantes apropien los comportamientos culturales necesarios para hacer parte activa de una sociedad letrada, esto es, a que no solo desarrollen su competencia lectora sino también a que comprendan el valor social de la lectura, y de la escritura en una sociedad alfabetizada, dependerá igualmente de lo que permitan sus condiciones. Es decir, de cómo la propuesta de la biblioteca explique y concrete su existencia en la institución escolar, sus vínculos con la lectura, la escritura, su rol en la formación y en la democratización del acceso al mundo de los libros y a la cultura y su modo de articulación con los intereses y expectativas de la comunidad educativa.

2 Cf. Una ampliación de la reflexión acerca del papel del adulto como lector en voz alta, como mediador entre los niños y los libros y como intérprete e interpretante, está desarrollada en Calonje, Patricia, "El sentido de leerles a otros en voz alta" en Revista Educación y Biblioteca, 157, enero-febrero 2007. Madrid.

\section{Pensar la contribución que la biblioteca escolar puede hacer a la formación lectora}

Planteado el símil, quiero llamar la atención ahora sobre la importancia de pensar la contribución que la biblioteca escolar puede hacer a la formación lectora, y para ello deseo presentar varias consideraciones. La primera es la necesidad de reflexionar sobre la viabilidad de la formación lectora en la biblioteca escolar, dadas unas condiciones sociales determinadas. Dado el carácter educativo de este espacio, su propia especificidad, determinada por su relación con la lectura y con la formación, hay que preguntarse, igualmente, por las condiciones que demanda crear y desarrollar este espacio.

La segunda consideración, articulada con la anterior, hace alusión a una indagación necesaria: valorar la biblioteca, tal como se materializa y como es concebida, con las imágenes que proyecta, con el papel que tiene en la formación lectora, con sus metas, con la concepción que tiene del aprendizaje, de la lectura y de la relación con el conocimiento, el tratamiento que hace de la lectura y, lo que es más importante, con las relaciones y las interacciones que propicia. No hay que perder de vista que la biblioteca puede contribuir a acercar a los estudiantes a la lectura o, también, a alejarlos.

Leer no es un acto natural y ahistórico, sino que está inscrito en contextos que le dan fuerza y lo sancionan como uno de los factores determinantes de cultura o que, por el contrario, ignoran su valor o lo desestiman. Puesto que es entonces un producto de la actividad humana, habrá que considerar entonces si la biblioteca escolar expresa o no en su materialización condiciones para contribuir a la construcción de un lector y a su participación en el mundo letrado. El contacto con el mundo de los libros y con la lectura, y la relación con esta práctica desde la infancia y, consecuentemente en el mundo escolar, constituyen un desafío inmenso para sociedades como la nuestra, cuya organización social, cultural y económica y modos de intercambio exigen cada vez más de los individuos, no solo poseer un conocimiento y dominio básico del código escrito, sino, lo que es más importante, estar en condiciones de participar en las prácticas culturales, esto es, en 
aquellas en las que leer y escribir son decisivos par el ejercicio de la ciudadanía (Pérez, 2004).

El desarrollo de la biblioteca escolar (su creación y/o su renovación) plantea retos que comprometen tanto al Estado como a la institución escolar. Por parte del primero, urge la definición de una política nacional de lectura que reconozca el valor de la formación lectora en una sociedad alfabetizada y su responsabilidad en la creación y desarrollo de bibliotecas escolares, expresada en una legislación que lo garantice y en la destinación de partidas presupuestales adecuadas para lograrlo. De parte de la institución escolar, se requiere también su gestión decidida para comprometer y asegurar la participación del Estado, para impulsar y sostener la creación de otros espacios de lectura, para reconocer y consagrar un tiempo importante a la actividad lectora.

En este punto del análisis conviene mencionar cómo en Colombia, aunque la lectura, la escritura y la expresión oral constituyen objetivos primordiales de la escolaridad, la biblioteca no ha logrado tener todavía una presencia significativa en las instituciones escolares, en particular en las de los niveles de preescolar, básico y medio. Lo cierto es que pese a las iniciativas de algunas por crear bibliotecas y hacer de ellas centros vitales de los que se nutran todas las actividades de cotidianidad escolar, en otras, éstos espacios siguen considerándose todavía como las cenicientas de las instituciones, por lo que es frecuente encontrar que la biblioteca ha sido convertida en un depósito de libros, en un lugar para hacer tareas, o en un recinto de destierro y de castigo. Para dar solo un ejemplo, en Colombia, en el 2001, no más del $5 \%$ de las instituciones educativas tenía una biblioteca escolar. ${ }^{3} \mathrm{~A}$ lo anterior hay que sumar el restringido presupuesto que el Ministerio de Educación Nacional asigna para su creación y su desarrollo, aunado al limitado reconocimiento que en la práctica hace al papel que cumple la biblioteca escolar en la formación lectora.

3 Melo, Jorge Orlando. Las bibliotecas públicas colombianas: ideales, realidades y desafíos. En: Aguado, Álvaro et ál. (2001). Bibliotecas públicas y escolares. Bogotá: Fundalectura, p. 114.
Objetivos fundamentales, susceptibles de ser asignados a la biblioteca escolar (como son la democratización del acceso al mundo de lo escrito y a la cultura, el apoyo intencional a aprendizajes que enseñen a usar la información para la construcción del conocimiento, la familiarización con lo escrito bajo todas sus formas, la posibilidad de uso y dominio de distintas fuentes de información, la adquisición de distintos modos de lectura, la construcción de relaciones duraderas y significativas con los libros y la lectura y la formación para la investigación y el aprendizaje autónomo) son todavía difíciles de lograr debido precisamente al desconocimiento que en el mundo escolar hay respecto al papel que puede desempeñar este espacio en la formación lectora. Aunque en las tres últimas décadas se constatan desarrollos teóricos que apuntan a una revalorización del papel de la biblioteca escolar, lo cierto es que en Colombia no puede decirse lo mismo de su realidad empírica.

\section{Condiciones de las que la biblioteca requiere dotarse para contribuir a la formación lectora}

Cuando hablo de condiciones me refiero a la posibilidad de que la biblioteca se dote de unos ámbitos propicios, unos tiempos disponibles y unas mediaciones apropiadas, que hagan de la lectura una práctica que transcienda los muros de la escolaridad, “... no solo porque cimienta, por obra de la alfabetización, toda construcción futura de la sociedad, sino, además, porque es, para muchos miembros de la sociedad, el primer y el último circuito de lectura en que se les dará la ocasión de insertarse (si se descuenta el omnipresente de los medios)" (Montes, 1999: 11). Sin embargo, es importante subrayar que solo se trata de condiciones y factores propicios para el desarrollo de la formación lectora, y que ninguna receta podrá garantizar resultados óptimos.

Ahora bien, como el proyecto de biblioteca escolar tiene una dimensión institucional, el desafío de diseñarla y concretarla, aunque es responsabilidad de la persona que está a su cargo y de aquellos que apoyan su trabajo, también compromete a fondo a 
toda la comunidad educativa, en especial a directivos y profesores. Esto se traduce en la disposición de crearla y mantenerla adecuadamente, en la convicción de que es posible desarrollarla, en la voluntad de realizar todo tipo de gestiones para su consolidación y en compartir la responsabilidad con todos aquellos que pueden contribuir a la dinamización de un proyecto que, por sus características, involucra a toda la escuela.

Como puede colegirse, no solo se trata de la consecución de unos libros, de un espacio para la biblioteca, de un bibliotecario que la dirija, para luego ser abandonada a su suerte. El compromiso va mucho más allá, pues supone la creación de entornos favorables al aprendizaje, la instauración de interacciones gratificantes y con sentido con los textos escritos, la adquisición de competencias en el manejo de las nuevas tecnologías de información y comunicación, la creación de un ambiente lector que, además de involucrar por su mediación a estudiantes, profesores, padres de familia, lo haga también con otras personas que puedan coadyuvar a que la actividad de la biblioteca tenga sentido para todos. Habrá condiciones también si, a la par con esta disposición, promueve, con la colaboración de los profesores, la comprensión y la valoración de sus beneficios como espacio que por ser parte de la institución escolar comparte los objetivos de educar y formar ciudadanos, con acciones y estrategias intencionadamente diseñadas para alcanzar sus propósitos.

Pero las posibilidades de lograr sus propósitos serán bastante limitadas, por no decir inexistentes, si, primero, no hay una reflexión sobre el papel que puede jugar en la formación del estudiante y en los procesos escolares, y, segundo, si no dispone de ciertos elementos que en su desarrollo puedan ofrecer condiciones propicias para la formación lectora. $\mathrm{Su}$ propósito fundamental no se alcanzará por el solo hecho de contar con estos elementos de cualquier manera. Solo podrá lograrlo asegurando el acceso a bienes materiales y simbólicos, contando con un presupuesto adecuado para su creación, desarrollo $\mathrm{y}$ fortalecimiento, un espacio, un tiempo y una dotación adecuados y acordes con las necesidades de la institución escolar, un personal idóneo y una oferta de servicios y programas que permitan afectar universos imaginarios, discutir, replantear reglas de juego, tradiciones, prácticas, ideas acerca de la lectura y los lectores, cánones, costumbres, políticas, circuitos de lectura, oferta editorial. ¿Qué sentido tiene pregonar su contribución a este propósito si, a la par que se invita a los niños a leer, se les niega la posibilidad de hacer préstamos a domicilio o se les impide su acceso a los materiales escritos al permanecer estos bajo llave?

\section{Pensar el sentido de las prácticas que propicia la biblioteca escolar}

$\mathrm{Al}$ constituirse como un centro de recursos documentales, la biblioteca escolar hace posible el contacto con una diversidad de objetos culturales que simbolizan la memoria del ser humano. Al ofrecer la posibilidad de conocer la riqueza cultural encarnada en los materiales escritos, en tanto espacio que representa la estabilidad del saber, así sea provisional, pues este es revaluado permanentemente, brinda a sus usuarios la oportunidad de ampliar su conocimiento y su representación del mundo y de la vida, de desarrollar su sentido de identidad como seres humanos y su pertenencia a la cultura. Un trabajo de exploración de la memoria que son los textos puede ser valioso para ayudar a estudiantes y maestros a descubrir y a comprender el devenir de la condición humana, lo que son como sujetos sociales, lo que pueden ser, y a elaborar o reelaborar su presente y su futuro. En este sentido, la relación con la biblioteca escolar será tanto más rica y fecunda cuanto más equilibrada, variada y estimulante sea su colección y la programación ofrecida, cuanto más favorable y amable sea la acogida brindada y más ajustado sea su plan de trabajo a las necesidades y expectativas de la comunidad educativa.

Situar en primer plano el propósito de participar en la construcción de lectores implica a la biblioteca escolar crear condiciones para fomentar la lectura de todo tipo de material escrito, lo que supone contar con una colección variada y diversa, de calidad, abierta a toda la comunidad educativa, y con una programación diseñada para relacionar a 
los estudiantes con distinto tipo de textos, de modo que puedan conocer y disfrutar las posibilidades de cada género. Los contactos con variados textos de un mismo género leídos por distintos estudiantes pueden ser la vía para la formación de criterios de selección o de recomendación de títulos, comportamientos propios de un lector avezado. La lectura de obras completas y su discusión en experiencias colectivas puede propiciar uno de los aprendizajes esenciales de un lector: aprender a leer obras y a hablar de ellas, esto es, a resumirlas, reseñarlas, comentarlas, y a explorar y discutir intertextualidades posibles.

La interacción con diferentes tipos de textos es un ejercicio fecundo para la formación de un lector, pues le brinda la posibilidad de conocer cómo escritores expertos escriben sus textos y expresan una sensibilidad frente a los asuntos humanos -escritura y sensibilidad de la cual los lectores van apropiándose, inclusive y sobre todo, de una manera inconsciente, de tal forma que, puestos en el acto de escribir, hacen uso de ellas durante su propia producción-. Al entablar los estudiantes un diálogo con los libros leídos, por la mediación de un adulto o un par, al comunicarse con autores de varias generaciones, de otras épocas, se facilita la ampliación de sus mundos y se enriquece su representación de la realidad, favoreciendo contactos que les permiten comprender lo que significa compartir una misma herencia cultural y hacer parte de una comunidad de lectores. Esta actividad realizada en forma permanente adquiere el sentido de un ritual que en su repetición se resignifica en todo momento.

Es importante señalar aquí que la referencia a diversidad de material escrito no incluye los textos escolares, ni las cartillas ni los manuales, pues no hacen parte de la colección de una biblioteca escolar. Su lugar es el bibliobanco. Hago alusión a este aspecto por la prevalencia en la escuela colombiana de este tipo de textos y por las implicaciones que esto tiene en la formación del estudiante: la exclusión de otras fuentes impide conocer un mundo infinito de percepciones y, por tanto, le arrebata la posibilidad de enriquecer su mirada y hacer compleja su formación. Al ignorar la riqueza de otros materiales escritos, se privilegia el aprendizaje de una única modalidad de lectura y de un único tipo de texto y se deforma con ello la actividad lectora (Lerner, 1995).

El hecho de ofrecer materiales escritos de calidad, sobre todo aquellos que crean un interés duradero por la lectura, y que satisfacen las necesidades de información, de formación y de recreación de los estudiantes, convierte a la biblioteca en un espacio que pueden hacer suyo cuando descubren un mundo por explorar, cuando experimentan el goce de construir el conocimiento por sí mismos, con independencia creciente de quienes apoyan su proceso formativo y cuando descubren en los libros la oportunidad para satisfacer distintos intereses y necesidades.

Sin poner frenos a la posibilidad de elección de los estudiantes, la biblioteca, al operar con una colección abierta, abre un espacio formativo en el que tienen oportunidad de manipular, de hojear, de aprender a seleccionar el material escrito y de escoger las obras de su preferencia. Poniéndolas a su disposición por medio del sistema de préstamo externo, la biblioteca incentiva la práctica de la relectura, haciendo posible la interacción con el material escrito por fuera de la Escuela, lo que puede seguramente dar lugar a intercambios en el grupo familiar del estudiante o con sus pares. Uno de los aspectos más valiosos de esta experiencia es que al delegar en el estudiante la responsabilidad del material escrito y de su conservación, se crean condiciones para estimular el cuidado de los objetos de la biblioteca y la comprensión de su valor como bienes públicos.

La biblioteca también puede contribuir a neutralizar la noción de tiempo que se maneja en la sociedad y que permea también la cotidianidad escolar.

\footnotetext{
"Una noción de tiempo que (...) deja un espacio mínimo a la lectura pues, estrechamente relacionada con la fugacidad, se rinde en ella culto a todo aquello que es efímero y evidente. Lo que requiere interpretación, entonces, lo que no es obvio no vale la pena que sea tomado en consideración. Si asumimos que la lectura demanda entablar un diálogo que exige esfuerzos de reflexión, podemos pensar que una sociedad que ha construido
} 
un concepto de tiempo basado en lo efímero, necesariamente tiene que promover un ideal de lector basado no en la reflexión, sino en una aproximación rápida al texto. ¿Cómo contrarrestar el peso de esta cultura en experiencias realizadas con niños y con jóvenes en la biblioteca escolar y en otros espacios? Alejandro Delgado (1998), de quien retomo estas ideas, propone realizar movimientos para introducir el metatiempo de la lectura en el tiempo real, lo que en términos prácticos significa encuentros con la palabra escrita, regalos de tiempo a través de sesiones de lectura en voz alta basadas en la gratuidad, en no pedir nada a cambio, pensar el tiempo de otra manera, de tal forma que dé margen al diálogo en silencio con un libro, a comentarlo consigo mismo o con otros, a reseñarlo, a divulgarlo" (Calonje, 2007).

Esto puede implicar también la conquista de un tiempo para la lectura en la escuela. En este sentido la biblioteca puede desplegar una actividad importante con visitas a otros espacios de lectura de la ciudad, bibliotecas públicas, librerías, ferias del libro, exposiciones, y con experiencias que enseñen a los estudiantes de qué están hechos los libros, cómo se hacen, qué hace posible su divulgación, etcétera.

La posibilidad de disponer de un plan de trabajo establecido en función de una organización flexible del tiempo, que contemple distintas modalidades organizativas ofrecidas en función de las necesidades del programa escolar, garantiza que la biblioteca escolar pueda contar con una propuesta que contribuya al desarrollo de proyecto educativo institucional y del programa escolar. No hay que olvidar que el modo en que se distribuye el tiempo de la biblioteca, así como el que se le asigna a los estudiantes para frecuentarla, expresan la importancia que la escuela le asigna a esta. El hecho de destinar un tiempo específico y preestablecido para la lectura recreativa, para el desarrollo de técnicas y habilidades de búsqueda, consulta y estudio y para la visita a la biblioteca y a otros espacios de lectura, dice mucho de la concepción y la valoración que tiene de ella.

La biblioteca escolar se constituye en un ambiente propicio para la lectura al dotarse de modalidades organizativas de muy diversa índole, de distinta duración, que le permiten desarrollar simultáneamente proyectos de corto, mediano o largo plazos, actividades permanentes, actividades secuenciadas, actividades ocasionales o de sistematización (Lerner, 1995). El ofrecimiento de diferentes modalidades organizativas convoca a los estudiantes a participar en una variedad de experiencias con el material escrito, a la vez que permite a la biblioteca apoyar el desarrollo de propuestas de muy diversa duración en las que, al ejercitar distintas modalidades de lectura, pueden ampliar su conocimiento sobre los diversos usos que tiene esta en la vida social y aprender la localización, uso y evaluación de los recursos documentales disponibles.

En la estructuración e implementación del plan de trabajo es decisiva la participación del bibliotecario, quien ha de ser una persona idónea y competente para el cargo para así poder definir conjuntamente con la institución escolar unas prioridades para la biblioteca. El conocimiento acerca de la organización y el funcionamiento de la institución escolar y de los propósitos y la labor que realiza serán indispensables para estructurar y orientar los servicios y la programación de la biblioteca. Para apoyar los procesos educativos y hacer de la biblioteca un espacio de fomento de la lectura que vaya más allá de la investigación de temas del programa escolar y de la solución de tareas, el bibliotecario ha de ser capaz de gestionar y conseguir recursos, planear y proponer proyectos de manera concertada con la institución escolar, y diseñar un modelo de atención que permita ofrecer servicios y programaciones que tengan en cuenta necesidades escolares, extraescolares y comunitarias (Venegas, 2003).

Hay que tener en cuenta, además, que la posibilidad de que los estudiantes puedan asumirse como usuarios plenos de derecho de la biblioteca escolar, es decir, como lectores, está relacionada directamente con el conocimiento que tengan sobre su funcionamiento general y su uso. De allí la importancia de darles a conocer sus servicios, su organización y funcionamiento, sus normas de uso, organización y clasificación de su colección, su programación, suministrándoles información sobre el uso de los materiales, sobre el servicio de préstamo interno 
y externo, y definiendo formas de colaboración mutua con la biblioteca. Resulta también indispensable que les procure los medios necesarios para resolver problemas ligados con la búsqueda de la información y con su manejo como dinamizadora de conocimiento.

\section{La biblioteca escolar, un espacio de aprendizajes para hacerse lector, para ser lector}

Si la razón de ser de este espacio es apoyar no solo los procesos para aprender a leer y a escribir, sino también para hacerse lector y ser lector, todo el proyecto ha de concebirse como parte de un engranaje cultural y educativo destinado a cultivar la lectura y la escritura, así como el encuentro con múltiples experiencias relacionadas con la información, la ciencia y la cultura. Siendo uno de los propósitos de la biblioteca escolar apoyar al profesorado en procesos que guían al niño en el conocimiento, interpretación y producción de símbolos escritos y su participación en prácticas culturales, tiene también un papel que jugar en la creación de espacios que cultiven estas capacidades y que exploren todas las posibilidades que brindan en relación con lo estético, lo lúdico, lo afectivo y lo racional (Dubois, 1995).

Dotada de una propuesta en constante movimiento, desplazamientos, cambios, redefinida en función de las necesidades de formación e intereses de los estudiantes, la biblioteca escolar crea condiciones favorables para la formación lectora cuando propicia la lectura comprensiva, la construcción del significado del texto, cuando da cabida a la realización de distintas prácticas en las que se fomenta la interacción lector-texto por la mediación del bibliotecario, de otras personas que apoyen su trabajo, de los maestros, de los padres de familia, o de sus pares: lectura en voz alta, lectura compartida, presentación de libros, etc. Al dar cabida a prácticas como estas, la biblioteca escolar, a la vez que estimula diversas formas de leer, deviene el espacio en el que se reconocen los derechos del lector, entre ellos el de hacer su propia lectura, es decir, el de aceptar el desafío del texto, su inmanencia, sus escollos, y de responder a ello con el despliegue de sus propias estrategias.
Por los aprendizajes fundamentales que proporciona, la lectura en voz alta puede ser una práctica privilegiada para fomentar la formación de lectores. Participar en un acto de lectura en voz alta permite relacionarse con el lenguaje escrito, con sus particularidades semánticas y sintácticas, con sus diferentes posibilidades de uso y, también, contar con una mayor riqueza de vocabulario, que no es otra cosa que la posibilidad de enriquecer la representación que se tiene del mundo y de la vida. Es el espacio para apreciar el poder de las palabras, para ampliar la visión y comprensión del mundo y de la vida al conocer nuevas formas de nombrarlo, familiarizarse con giros y expresiones idiomáticas que no hacen parte del lenguaje oral, apreciar los ritmos internos de la lectura, diferenciar las modalidades propias del habla de las que son específicas del lenguaje escrito, aprender a entonar oyendo a otro leer, escuchando cómo el lector se asume como narrador. Las sesiones de lectura en voz alta en una biblioteca pueden dar lugar a conversaciones en torno a la obra leída, en las que se expresen comentarios e impresiones, sentimientos y emociones y se discutan distintas interpretaciones, que se buscará que sean validadas o desechadas por los mismos estudiantes con apoyo del texto leído.

Contraria a la idea de que la lectura tiene solo una dimensión, la reflexiva, la biblioteca escolar puede contribuir a crear con los textos una relación no solo cognitiva, sino también afectiva, emotiva. Acorde con esta idea, se leen en la biblioteca libros en los que niños y jóvenes se encuentran, libros que los sorprenden de la misma forma que la vida lo hace, que permiten aprender a ver la vida a través de ellos, libros que permiten diversidad de interacciones, unas veces apelando a la razón, otras a la emoción, que los sobresaltan, los hacen sobrecogerse, los atrapan, los hacen entrar en diálogo con el mundo. Sin buscar mitificar la lectura ni la función del libro, excluyendo otras prácticas y la relación con objetos que pueden volver más creativa la vida de una persona, es innegable que el enriquecimiento de la visión personal gracias a la ampliación de la percepción sobre los fenómenos sociales, obtenida a través de la lectura, solo puede traer como consecuencia una 
mejor capacidad de entendimiento de la condición humana. Con la convicción de que experiencias como estas pueden ayudar a contrarrestar los efectos de una realidad tan violenta como la que se vive en este país, la biblioteca deviene un lugar en el que se alientan en quienes están formándose experiencias vitales, aprendizajes indispensables para la vida y para la convivencia. Una de las experiencias más fecundas es la de estar en contacto permanente con lectores más avezados, que pueden ser sus mismos pares o adultos, que recomiendan lecturas, que incitan búsquedas y que resuelven inquietudes o señalan caminos para explorarlas. Alentada por la biblioteca escolar, la actividad incesante que produce cooperar con otros en la búsqueda de conocimiento, en la producción de textos, en procura del desarrollo de habilidades para utilizar los recursos informativos o la que se despliega con la elaboración de proyectos que permiten el desarrollo de habilidades cognitivas y metacognitivas, relacionales y ético-sociales, crea un espacio formativo, lugar de relaciones y de reciprocidad interindividual, favorable para educar en la solidaridad, la colaboración y la convivencia (Lombello, 2004)

Entre las tareas fundamentales con las que la biblioteca puede contribuir a la formación lectora está la de propiciar rupturas con algunas de las prácticas lectoras que se privilegian en la escuela, buscando con ello que puedan ser revaluadas. En este sentido, otorgar un lugar preferente a la lectura voluntaria, considerada por lo general como una práctica que poco aporta a la formación de un lector y a la cual se le da, por consiguiente, muy poca cabida en el trabajo de aula, ayuda a canalizar intereses y a satisfacer inquietudes personales. Esta práctica, que representa el encuentro íntimo de alguien consigo mismo y con un autor, $y$, a la vez, el espacio privado de relaciones con un texto, la oportunidad de seleccionarlo, es fundamental para la formación de un lector precisamente porque le ayuda a descubrir lo que Pennac (1996: 17) denomina “... la virtud paradójica de la lectura que consiste en abstraernos del mundo para hallarle un sentido". La posibilidad de darle vida a un libro cuando se lee, de darle plena existencia, es también la oportunidad para el que lo hace de convertirse en un lector, sin cuya participación activa en la construcción de su significado, aquel no existiría.

La biblioteca escolar puede también contribuir a formar a niños y jóvenes en el conocimiento de la literatura infantil y juvenil. Estos encuentros facilitarán su apertura a la infinita diversidad del territorio de lo imaginario, lo iniciarán en las alegrías del viaje vertical, lo dotarán de la ubicuidad, lo sumergirán en "la soledad fabulosamente poblada del lector" (Pennac, 1996). La participación de este espacio en la educación literaria de los estudiantes es decisiva porque puede incentivar la lectura de sus distintos géneros tanto en su forma oral como escrita. Al hacerlo estará favoreciendo el acceso al imaginario colectivo configurado por la literatura y el aprendizaje de los modelos narrativos y poéticos de la literatura propia tanto de su propia cultura como de otras (Colomer, 1999).

Aludo nuevamente al jardín secreto y a lo que representa en términos de espacio de conocimiento, de transformación personal, de formación, para señalar cómo la búsqueda de la puerta que conduce a su interior es una metáfora de la capacidad de indagación que tiene el ser humano y del deseo que surge en él por aprender y explorar aquello que le resulta atrayente. También es la metáfora de un espacio donde uno puede encontrar sus raíces, el sentido de las cosas, con el que los niños y jóvenes se sienten identificados cuando se les reconoce plenamente su capacidad para intervenir en su propio desarrollo y transformación. La biblioteca escolar estará fomentando la formación lectora si les ofrece condiciones para convertirse en seres curiosos, que exploran, que preguntan, que cruzan umbrales, que abren puertas, que no se contentan con una sola respuesta, que expresan sus puntos de vista, que no temen equivocarse. En este sentido, concebir la lectura como búsqueda de conocimiento y no solo de información es la posibilidad, desde la perspectiva de la formación de un lector, de desplegar una actividad que en la biblioteca escolar es posible fomentar si se establecen relaciones de intercambio de saberes, a partir de experiencias que den pie a la expresión de ideas, inquietudes, temores, hallazgos, y a la desacra- 
lización de este espacio. Al alentar esta capacidad de búsqueda de conocimiento y al propiciar situaciones que permitan reconocer la complejidad de los saberes, la necesidad de ser selectivos en el manejo de la información, de polemizar y de saberse orientar en la búsqueda de información, la biblioteca es crítica con aquellas prácticas que, según el filósofo Kart R. Popper, citado por Lombello (2004: 189), hacen parte de una pedagogía todavía con cierta vigencia en la escuela. "Nuestra pedagogía", plantea Popper, "consiste en dar a los niños respuestas sin que ellos hayan preguntado y en no escuchar las preguntas que ellos hacen. Esta es la pedagogía que rige en la práctica presente: respuestas sin preguntas y preguntas sin respuestas" (Lombello, 2004).

\section{La biblioteca escolar como espacio de mediaciones significativas}

No es suficiente con que la biblioteca escolar exista de cualquier manera, ni es garantía de nada que cuente con buenas condiciones locativas, una colección variada y de calidad y con un servicio de préstamo externo si no ha desarrollado otros elementos que son los que van a hacer que su trabajo, desde la perspectiva de su contribución a la formación lectora, adquiera realmente sentido. Las condiciones mencionadas son básicas pero no suficientes porque es fundamental que tenga un proyecto de trabajo fundamentado en el conocimiento de la institución escolar. Además de ser un apoyo al programa escolar, ha de ser parte constitutiva del engranaje que permite dinamizar relaciones significativas con la información, presentada en una variedad de formatos y medios (Venegas, 2005). Uno de los componentes esenciales del proyecto es contemplar programas y proyectos para poner en movimiento el espacio de la biblioteca, para poblarla de lectores asiduos, que participen de una amplia y variada gama de actividades que incentive relaciones significativas con mediadores que en sus actuaciones y con sus actuaciones enseñen a los estudiantes a amar los libros, a la vez que estimulen en ellos el deseo de leer y de saber.

Si la biblioteca concibe la lectura como experiencia de búsqueda cognitiva, afectiva, lúdica, podrá, con la ayuda de mediadores "convertidos en libros"; como dice Pennac (1996), hacer surgir el deseo de leer en niños y jóvenes, ayudar a restañar en algunos "heridas de amor" -léase pérdidas momentáneas del amor a la lectura- originadas en y por una relación frustrante con la lectura, posibilitando que paulatinamente se abran a todos los textos y que se ofrezcan a sí mismos lo que considera este mismo autor la gratificación última de un lector: ser capaz de abandonar un texto para ir al encuentro de otros, con una actitud de búsqueda que le produce innumerables gratificaciones y hace significativa esta experiencia.

A mi modo de ver, uno de los aprendizajes fundamentales que la biblioteca puede incentivar en el estudiante para que adquiera como lector la vocación de alquimista, característica deseable, según Pennac (1996), es fomentar en él la capacidad de búsqueda y de observación, la lectura atenta, la certeza del derecho de tener un lugar en el espacio en el que al mismo tiempo que se le da la oportunidad de escogencia se educa su sensibilidad. El desarrollo de esta capacidad de búsqueda puede cultivarse, por ejemplo, con el ofrecimiento de trayectos de lectura que pueden ser sumamente estimulantes al concentrar la atención en un tema en particular o en la relación de temas conexos.

Por todo lo anterior, la función del bibliotecario como mediador tiene una dimensión fundamental en el trabajo de la biblioteca escolar. "El mediador es aquel que tiene la responsabilidad de contribuir a la creación de condiciones que amplíen horizontes de vida, de lectura, de sentido, a partir de experiencias con textos y palabras que nos interroguen, que ejerzan influencia en nosotros, que inviten a leer otros libros, a leernos, que estimulen el deseo de seguir leyendo. Para ser mediador entre los niños y jóvenes y el mundo de los libros es absolutamente indispensable ser lector porque de otra manera no hay posibilidad de expresar amor o pasión por estos objetos culturales. El mediador debe expresar interés y un respeto profundo por los libros sin sacralizarlos, sino, por el contrario, mostrando lo cercano que se puede estar de ellos. La implicación del mediador es decisiva como lo es la reflexión y la acción sobre el 
tipo de libros que va a poner a disposición de niños y jóvenes y las formas de presentarlos, de conversar en torno a ellos" (Calonje, 2007: 3).

Apelo nuevamente aquí a la ficción para hablar esta vez de una película, La sociedad de los poetas muertos, ${ }^{4}$ y de la imagen que ofrece al espectador acerca de cómo un profesor asume el papel de mediador cultural para despertar en sus estudiantes la pasión y el interés por la lectura. Aunque la película no hace alusión a un bibliotecario, me parece que lo que allí se plantea es extensible a él o a cualquier otro adulto dispuesto a asumir este papel: mostrar los aspectos fundamentales del comportamiento lector, desempeñarse como modelo lector y ser capaz de servir de puente, de crear vínculos comunicativos entre un grupo de estudiantes y los libros, enseñándoles a conocerlos y a valorarlos.

De acuerdo con lo planteado, es imprescindible que el mediador sea un lector y actúe como tal para que de esta manera pueda mostrar a los estudiantes los comportamientos propios de esta práctica, transmitir la pasión por la lectura con todas las implicaciones que esto tiene. En este sentido, es necesario que el bibliotecario sea alguien al que le apasione la lectura, conocedor de libros, un lector consumado, con permanente interés por conocer y analizar las últimas novedades del mercado, con conocimiento del contexto editorial infantil y juvenil y de obras de calidad. Si aspira a ser un mediador, necesita tener un amplio conocimiento del campo de la literatura infantil y juvenil y una comprensión del papel que juega esta en la formación estética y ética del estudiante; requiere una sólida formación para, entre otros, hacer comentarios críticos y reseñas sobre libros de interés para los profesores; promocionar y animar la lectura y la escritura, orientar a los alumnos en la selección de libros en función de sus necesidades de información y recreación; sugerir la compra de títulos para ampliar la colección de la biblioteca. Contar con conocimientos educativos y pedagógicos sirve al bibliotecario para saber mediar

4 La película La Sociedad de los poetas muertos, dirigida por Peter Weie y estrenada en 1989, está basada en la obra original de NH Kleinbaum, homónima suya. entre unos y otros, orientar adecuadamente sus demandas, responder a sus preguntas, encauzar sus intereses como lectores y atender sus necesidades de aprendizaje, información y recreación.

Las prácticas de lectura a cargo de profesores y bibliotecarios que se asumen en permanencia como lectores pueden dar lugar a experiencias que no solo enseñen a leer, sino también a amar la lectura. Compartirla con los estudiantes en vez de exigirla produce resultados gratificantes: surge o vuelve a surgir, según el caso, el deseo de leer, emerge la palabra en torno a libros y autores -nacen en el niño preguntas sobre el texto y se abre a la construcción de su significado-, se experimenta el goce de leer, propio del lector-alquimista, surgen y se expresan actos indicativos de lo que Daniel Pennac (1996) concibe como el surgimiento de la vocación de alquimista. Hay que tener en cuenta que en no pocos casos el niño corre el riesgo de perder la posibilidad de sentir el goce propio que produce la lectura, porque en vez de ser alentado, alimentado y mantenido, se impone su obligatoriedad, lo que vuelve penosa la lectura y genera, por tanto, su aversión. En este sentido, el bibliotecario o el maestro asumen el papel de mediadores cuando propician encuentros, proporcionan acercamientos diversos y la formulación de interrogantes. Hacen surgir curiosidades, inquietudes, pasiones, así desconcierten, admiten recorridos por caminos no convencionales, hacen posible la emergencia de la curiosidad que es uno de los fundamentos de la cultura, fuente del deseo de leer (Geneviève, Patte, 2).

Ahora bien, hay que ser conscientes de que estas experiencias serán tanto más provechosas cuanto mayor sea la disposición de profesores y bibliotecarios para avanzar en su formación profesional y personal. Esta necesidad de una formación teórica que permita la reflexión sobre la práctica es inaplazable, pues la reflexión acerca de la contribución que puede hacer la biblioteca a la formación lectora pasa por su problematización. Como su creación y desarrollo de la biblioteca no es resultado de la aplicación de recetas, sino de la discusión de las concepciones que están determinando su forma de existencia y de los cambios que puedan suscitarse 
a partir de esta reflexión, la preparación de sus mediadores, bibliotecarios y maestros, es una necesidad apremiante.

Lo planteado aquí suena difícil de lograr pero no es imposible. De ello dan prueba varias experiencias que a lo largo y ancho del país son la expresión de los ingentes esfuerzos de instituciones educativas, así no sean numerosas, que se debaten para que sus bibliotecas escolares puedan contribuir significativamente a la formación lectora. Aunque es indudable que su creación y desarrollo es un problema que concierne a distintas instancias, también lo es que

\section{Bibliografía}

Álvarez, Didier. (1993). Lectura y desarrollo: la causa bibliotecaria. En Memorias Primer Congreso Nacional de Lectura. Lectura, Democracia y Desarrollo. Bogotá: Fundalectura.

Baró, Mónica et ál. 2004. Bibliotecas escolares, ¿para qué? Madrid: Grupo Anaya.

Calonje, Patricia. (2007).El sentido de leerles a otros en voz alta. En revista Educación y Biblioteca 157, enerofebrero. Madrid.

Calonje, Patricia. (2007). Un reencuentro transformador: jóvenes universitarios y literatura infantil y juvenil. En Memorias V Seminario Internacional de Lectura y Patrimonio. Literatura infantil: nuevas lecturas y nuevos lectores. Cuenca: Universidad de Castilla-La Mancha. (En prensa).

Colomer, Teresa. (1999). Introducción a la literatura infantil y juvenil. Madrid: Editorial Síntesis.

Cuadernos de Pedagogía. Monográfico. Bibliotecas escolares. Presente y futuro. Opiniones. Experiencias y recursos. Número 352, diciembre 2005. Barcelona.

Delgado, Alejandro. (1998). ¿Por qué no leen a los clásicos? En Clij, Año 12, No. 113, febrero de 1998. pp. 18-25.

Dubois, María Eugenia. (1995). Sobre lectura y escritura: enseñanza y educación. En Memorias del $2 .^{\circ}$ Congreso Nacional de Lectura. Lectura, Escuela y Biblioteca. Bogotá: Fundalectura y Grupo Editorial Norma.

Escardó I BAS, Mercé. (2003). La biblioteca, un espacio de convivencia. Madrid: Anaya.

Hodgson Burnett, Frances. (1994). El jardín secreto. Madrid: Siruela, Colección Las tres edades.

Lombello, Donatella. 2004. Biblioteca escolar en el entorno social. En Memorias del $6^{\circ}$ Congreso Nacional de Lectura para Construir Nación. Bogotá: Fundalectura. es un asunto que nos concierne a todos los que trabajamos en educación. Por ello estoy convencida de que en tiempos de tanta incertidumbre y zozobra como los que vivimos, quienes tenemos un compromiso con la niñez y la juventud de este país, con su formación, necesitamos hoy más que nunca reivindicar la importancia de la biblioteca escolar y trabajar denodadamente por ayudar a contrarrestar los factores y situaciones que han impedido su creación u obstaculizado su adecuado funcionamiento. ¡No podemos ni debemos dejarnos vencer por el desaliento o por la desesperanza!

Lerner, Delia. (1995). ¿Es posible leer en la escuela?. En Memorias del 2. ${ }^{\circ}$ Congreso Nacional de Lectura. Lectura, Escuela y Biblioteca. Bogotá: Fundalectura y Grupo Editorial Norma.

Martín Garzo, Gustavo. Instrucciones para enseñar a leer a un niño. En www.unizar.es/cce/vjuan/ instrucciones_leer.htm p.2.

Montes, Graciela. (1999). La frontera indómita. En torno a la construcción y defensa del espacio poético. México: Fondo de Cultura Económica.

Osoro Iturbe, Kepa. (2002). La biblioteca escolar y el PEI en la formación de lectores. En $5 .^{\circ}$ Congreso Nacional de Lectura. Formación de lectores: Escuela, Biblioteca Pública y Biblioteca escolar. Bogotá: Fundalectura.

Patte, Geneviève. El rol del bibliotecario como mediador cultural En www.fundaciongsr.org/documentos/ seminario/cap4tema6.htm. SFP.

Pennac, Daniel. (1996). Como una novela. Bogotá: Grupo Editorial Norma.

Pérez, Mauricio. (2004). Leer, escribir, participar. En Memorias del $6 .^{\circ}$ Congreso Nacional de Lectura para Construir Nación. Bogotá: Fundalectura.

Rodríguez, Gloria María. (2002). Cara y cruz de las bibliotecas públicas y escolares. En 5. ${ }^{\circ}$ Congreso Nacional de Lectura. Formación de Lectores: Escuela, Biblioteca Pública y Biblioteca Escolar. Bogotá: Fundalectura.

Venegas, María Clemencia. (2003). La biblioteca escolar que queremos. Una visión para compartir. Bogotá: Fundalectura.

Venegas, María Clemencia. (2005). Por una ciudadanía plena. Hacia unas políticas distritales para las bibliotecas escolares Bogotá: Alcaldía Mayor de Bogotá, Secretaría de Educación. 